treatment was completed from the notes by us in order to see how well these factors were recorded.

No major differences were found among the hospitals or the specialties. In over a third of patients there was no record of disability in relation to breathlessness or mobility, or change of breathlessness before admission; in two thirds there was no record of a history of the presence or absence of ankle oedema. In only $12 \%$ had the usual (best) peak flow been recorded. Social support was not recorded in $48 \%$ and housing details not recorded in $59 \%$. The blood count and urea and electrolyte concentrations were usually recorded, but peak flow was not recorded in $33 \%$ and blood gas tensions on air were not recorded in $21 \%$. In patients given oxygen, repeat measurements of blood gas tensions were commonly not recorded. Before discharge, peak flow/forced expiratory volume in one second, and blood gas tensions were poorly recorded. Only $15 \%$ of case notes recorded that antismoking advice had been given to those patients who smoked on admission. In $42 \%$ of patients given steroids as part of acute management it was impossible to find plans for tailing off this treatment.

The use of antibiotics was almost universal in this series; $71 \%$ of patients received steroids (orally or intravenously), and bronchodilators were given in wide dosage, most patients receiving high dose nebulised $\beta_{2}$ agonist and anticholinergic treatment simultaneously with no attempt to quantify responses.

This study shows that the general standard of note keeping is poor. It would be impossible to measure outcomes with the data currently provided from most case notes of these patients. More careful assessment of this group of patients and a more critical approach to their treatment is required.

ISOBEL WILLIAMS Department of Thoracic Medicine, St Albans and Hemel Hempstead NHS Trust, St Albans, Hertfordshire AL3 SPN

ONN MIN KON St Mary's Hospital, London W2 $1 N Y$

DAVID EVANS Thoracic Department, Central Middlesex Hospital NHS Trust,
Acton Lane,
London NW10 7NS Central Middlesex Hospital NHS Trust,
Acton Lane,
London NW10 7NS

F J C MILLARD Department of Thoracic Medicine, St Georges Hospital, London SW17

\section{Scottish Confidential Inquiry into Asthma Deaths}

Each year 2000 people aged under 45 die in Britain as a result of asthma, about 50 of the deaths occurring in Scotland. Although several retrospective studies suggested that patients and doctors reacted inappropriately in the fatal attack, there is little evidence that practice is changing.

A confidential inquiry into asthma deaths has now been established in Scotland to review the circumstances surrounding the care of asthma patients during fatal attacks. Funded initially by the National Asthma
Campaign, the inquiry will be supported for the next two years by the Clinical Resource and Audit Group (CRAG) of the Scottish Home and Health Department. Its aims are to identify good practice and problem areas by exploring the background in cases of deaths of patients with asthma.

The inquiry will combine information gathering with local discussion of cases using a critical incident technique. Regional panels of general practitioners and respiratory physicians will review the information gathered and comments will be fed back to the clinical teams concerned. The findings will also be aggregated to identify any common themes. The results will be circulated widely to try to influence the management of other patients with asthma.

The inquiry represents a single strand in the process of reviewing and updating practice. By emphasising local consideration of the circumstances, combined with timely feedback from a regional panel, it offers theoretically a better prospect of influencing the care of other patients than, for example, publication of audit findings in medical journals. Also, by monitoring the circumstances of asthma deaths for several years it will be possible to judge whether practice is changing and whether this inquiry and other audit activities are having any impact.

Readers wishing further information should contact the area clinical audit coordinator (tel 041-248 7644 ext 2230).

CHRISTINE BUCKNALI Area Clinical Audit Coordinator

Scottish Confidential Inquiry into Asthma Deaths, Clinical Audit Office, 225 Bath Street,
Glasgow G2 $4 f T$,

$$
\begin{array}{r}
\text { Glasgow G2 4fT a copy, and son. } \\
\text { the Treasury. }
\end{array}
$$
asthma. seeing increases in infant mortality and child mortality in due course? We should not be complacent.

The health and wellbeing of children, enormously important in itself, is becoming the object of increasingly close scrutiny as we learn more of the ways in which adult morbidity and mortality may be related to factors operating in fetal life and in childhood. Although infant mortality and child mortality continue to fall, some forms of chronic ill health in childhood are becoming more common. Advances in the treatment of life threatening conditions, from extreme prematurity to cystic fibrosis, leave a growing number of survivors in need of continuing care, while environmental changes are probably responsible for the rising prevalence of

By collecting together data on child health from the Departments of Health, Social Security, Transport and Environment as well as from the national birth cohorts and from morbidity surveys the authors of this book have provided a valuable service to anyone wishing to scan the evidence relating to major child health problems, or wishing to know where to look for more detailed information. Separate sections cover overall population statistics, morbidity and mortality, and factors in the socioeconomic, physical and cultural environment of children as they relate to health. Most of the data are presented in graphical form with accompanying discussion. The writing is clear and the book is well referenced. Libraries in hospitals and health centres should get a copy, and someone should send one to

DUNCAN KEELEY General Practitioner

\section{BOOK REVIEWS}

Children, Teenagers, and Health. Caroline Woodroffe, Myer Glickman, Maggie Barker, Chris Power (pp 193; f16.99). Buckingham: Open University Press, 1993. ISBN 0335191258 (pb).

To read a collection of statistics from cover to cover is a rather odd experience likely to be confined to reviewers and other minority groups. It does, nevertheless, initiate interesting trains of thought. Between the age of 1 and 14 children from social class 5 are twice as likely to die as children from social class 1 ; their risk of death as a pedestrian in a road accident is four times higher, and their risk of death in a fire nine times higher. If poverty is defined as affecting households with under half the average income, the percentage of children in Great Britain living in poverty rose from $12 \%$ in 1979 to $26 \%$ in 1987 . Despite this, infant mortality and child mortality have continued their gradual downward trend over the past decade. Something must so far have protected children from the most serious health consequences of the relative increase in child poverty. Will we be

Medical Accidents. Charles Vincent, Maeve Ennis, Robert J Audley, eds (pp 293; f35). Oxford: Oxford University Press, 1993. ISBN 0192622897.

An important book that should be essential reading for medical directors, hospital chief executives, deans, and all those concerned with education in the health service, Medical Accidents examines the research on accidents and puts accidents in the context of operational health care. Medical accidents have the characteristics of accidents occurring in industry or transport but have not, until now, been given serious study and analytical thought. In medicine accidents are seen by doctors overwhelmingly in terms of litigation and financial settlements. There is also the feeling that someone is to blame. This book shows that accidents are the result of faults, failures, and omission in the way care is organised and delivered rather than a single person's responsibility. Blaming a clinician is too easy and can absolve the rest of the organisation from taking corrective action. Persistence in this way of thinking will not help to prevent accidents nor help professionals to understand and chang the conditions that lead to medical accidents.

Clinicians should think seriously about medical accidents as an opportunity for ensuring reflective learning and as an aid 